\title{
NARZĘDZIA PRACY ZAWODOWEJ W SYMBOLICE MĘCZEŃSTWA
}

1. W y $j$ a ś $n \in$ e 1 e $t$ e m a t u. Plerwotnym "językiem" chrześcijan w $1 \mathrm{ch}$ życiu kultowym dla wyrazania pojéc związanych z zycicm pozagrobowym 1 prawda teologiczna były symbole wyrazane w Ikonografii 1 epigrafil. If 1konografil chodzi głównie o freskowo malarstwo katakumb, w epigrafil zaś o rysunki umieszczone na tablicach grobowych w sąsiedztwie napisóv rytych ku czci zmarłych. Obok symbol1, które w sposób oczywisty wyrazaja zagadnienia zwizzano z męczeństwem, wykopaliska ujawniły wiele innych malowideł 1 rysunków, które suą treści za ziviazzane są z życiem codziennym. If tych ostatnich, określanych zwykle mianem scen historycznych, wystęuja niejednokrotnie narzędzia pracy zawodowej jak młotek, szczypce, piła, siekiera itp. Problemem, który budził od dawna spory wóród uczonych jest kwalifikowanie narzędzi wzį̨tych z źycia codziennego, w szczególności z źycia zawodowego, jako symboli męczeństira ${ }^{1}$. Nie chodzi tu - pojęcia 1konologiczne tj. o treść weirnątrzniz, 1deologicznź dyskutowanych poinników, alo jedynie o zewnętrzne kwalifikowanie malow1deł 1 rysunków do symboli męczeństwa, względnie do scen historycznych. Starsi autorzy wypowiadali siz niejednokrotnie w tej dziedzinie z pozycji nienaukowej apologetyki, kierując sle czesto w swych ooenach charakterem sprawowanych przez siebie funkcji zawodowych w administracjl kościelnej. Nie ma tu jednak jakiejśs ścłsłej cezury chronologicznej co do zmiany metody badaŕ powyżsej problematyki. I w końcu XIX w. występuja jeszcze autorzy, którzy 1konograficzne narzędzia pracy zawodowej interpretowali jako narz̨̧dzia męki, choć równocześnie wielu innych miało odı́ienne zdanie. Męczeństwo bowien od dawna było mykorzystywane jako poważne uzasadnienie kultowego

1. O samych znakach, por. F.Stopniak, Zabytki cmentarne jako dokumentacja do zycia zarodowego chrześcijan w gtarożytnośc1, "Archiwa, Biblioteki I Muzea Kościelne" 22/1971/169-186. 
życia Kościoła. I7 okresie wczesnego średniowiecza groby męczenników śclągały pielgrzymów do Rzymu, skąd zabierano i rozsyłano po całej Luropie tysiące relikwil do budujących się kościołów. Równiez w okresie Reformacji kult świętych męczenników odegrał niemałą rolę w walce $z$ protestantyzmem; a wreszcie XIX-wieczne badania nad katalcumbami połazczone z odkryciem nowych pomntków i świadectw walki chrześcijan o swoja wlarg, ożywiły w dużej mierze nauke 1 pobozność chrześcijaĺskiz. Nic więc dziwnego, że wielu badaczy w okresie XVII-XIX w. usiłowało tłumaczyé także narzędzia rzemieślnicze, będące wskaźnıkiem profesji zarodowej zmarłych, znajdujizce sie na $1 \mathrm{ch}$ tablicach grobowych Jako symbole męczeństwa.

IF 2. poł. XIX w. pojawlaja sie uczeni, którzy do znaków w ikonografil 1 epigrafii zaczęli podchodzló w sposób naukowy. Jednak rózricy infędzy nimi nie stanowi, jak juz wspominaliśny, jakaś granica czasowa, ale wyniki ich badań. Do pieriszej grupy należeli: Paweł Aringhi /1600-1676/. Slarek Antoni Boldett1/1663-1740/, Jan Bottari /1689-1775/, Józef March1/1795-1860/, Rafael Garrucc1/1812-1885/, Orazio Marucch1/1852-1931/ i Józef irllpert/Zwierzyna/ 1857-1941/. Do grupy drugiej natomiast weszli uczeni, którzy w większośc1 wywodzili sie ze szkoky Jana Baptysty Mossiego /1822-1894/.

$$
\text { 2. P o g l a d y a u t o r ó } \mathrm{d} a w \mathrm{n} \text { c h. W tworzacej }
$$
sie epigrafil chrześcijańskiej do czasów cesarza Konstantyna /+ 337/ wymieniano co najwyżej lmiona Piotra i Pawła. IV budowanych bazylikach konstantyiskich przy braliu odpowiednich inskrypcj1 1 jeszcze nieipykształconych symboli, trudno było rozróznić poszczególne osoby. W okresie starożytnyu przedstawiono ogólnie męczenników zwykle w koronach, w średniowieczu zaś 1ch znamieniem była palma. Najstarsze przedstawtenie męczennika z narzęiziem męik ukazuje obraz św. Wawrzyńca $\nabla$ mauzoleun Galii Placydii w lawennie. Teksty św. Bazylego, Grzegorza z Nyssy; św. Asteriusza biskupa oraz dane przekazane w inskrypcjach wskazujz, ze w pierwotnych kościołach wśród elementów dekoracyjnych były takize sceny mezczeristiva, w których przedstawiano męczenników równiez z narzz̨uziami mołki. Analogiczne sceny znalazły sie w miniaturach starych kodeksów ${ }^{2}$. IV literaturze przediniotu niewiele

2 Odsyłacze do podanycin tekstów, por. A.P.Frutaz, Martirio e martire. 3. Iconografia antica, ECat VIII 240-243. 
istniejé prac na temat wspomianych narzędzi. Do dnia dzisiejszego podstawowa pozycja jest praca napisana w $1591 \mathrm{r}$. przez A.Gallonio ${ }^{3}$.

U wymienionych wyżej autorów tendencja upatrywania symboli męczeństwa we wszystkich znakach jest cecha dominujaca. Stanowi to na pewno jedną z maźniejszych racji, która wielu autorom przeszkodziła w uwzględnieniu kwestii zawodowej u chrześcijan ${ }^{4}$. Np. obraz woźnicy cyrkowego był zawsze tłumaczony w znaczeniu religijnym, jako scena chrześcijańskiej duszy zmarłego koronowanej po śmierci 5 . Wojownik zaś, którego artyści przedstawiali w katakumbach ubranego w szaty podobne do stroju kapłana Starego Testamentu, interpretowany jest często jako zarząuca winnicy lub patriarcha Abraham, czy Mojżesz mysyłający szpiegów do ziemi obiecanej ${ }^{6}$. Tendencja ta wynikała w duzej mierze ze złego stanu zachowanych pomników, na co uskarżał się już znany rygorysta moralny prałat rzymski Jan Bottari. Przy zniszczeniu wierzchniej warstwy malowidła freskowego nie zatwo było rekonstruować szaty w portretach grobowych ${ }^{7}$, co utrudniało prace. Dotyczy to zwłaszcza rysunków 1 malowldex zachowanych jedynie w kopiach wykonanych przez poszczególnych badaczy. Wilpert nawet usikował sporządzić ich.pełny zestaw, ale w świetle krytyki przeprowadzonej przez Pawła Stygera wyniki tej pracy okazały sie niezadawa1 ajace ${ }^{8}$.

Według Wilperta róznica niędzy zoznierzem a orantem jest niewielka, gdyz wskazuja na nia tylko szaty. Przykład takiego malowidła zachował sie $w$ "Kaplicy Ostatniej Vieczerzy" na cuentarzu świętych Piotra 1 Marcellina. Przyezyna pomyłek popeznianych przez róz-

3 Antonio Gallonio, Trattato degli instrument1 di martirio, Homa 1591; przekład francuski, Paris 1904.

4 A.llarnack, Die Mission und Ausbreitung ges Christentums in den ersten drei Jairhunderten, Leipzig 1924, Bd. 2, 559-568: - przy analizie klas sporecznych nie omawia przedstawicieli zawodów.

5 J.milpert, Le pitture delle catacombe romane, Roma 1903, 491.

6 Tanże 483-484.

7 Cytuję za Wilpertem, Le pitture, t.2, 125.

8 P.Styger, Stan obecny 1 przyszłe zadania archeologi1 chrześcijaískiej, "Kwartalnik Teologiczny liteński" 2/1924/ 365-381. Według Stygera od śmierci Rossiego nie ma zadnego postępu wadaniach archeologit/Tamże 368, 370-371/. 
nych autoróv jest wg Wilperta wyłącznie zły stan zachowanych zabytków, który utrudnia identyfikację gatunku pracy. Zdaniem Wilperta wystarczy dogłabnie zbadać scenz malarską, by odkryć pełny sens przedstawionego obrazu9. Praktyka jednak wskazuje, ze to "zbadanie dogłębne" nie jest łatwe. Pouczającym przykładem, omówionym w artykulo Balboniego, moźc tu być historia odczytywania pewnego malowidła $\mathrm{a}^{10}$. Otóż lírucchi w 1879 r. pisał: "Osoba siedząca na katedrze wkłada rz̨ce na plecy osoby drugiej, jak gdyby dla zadania gwałtu... Scena ta iskazuje na wydarzenie historyczne 1 odnosi się do męczeństwa papieża Sykstusa II /257-258/"11. W $1915 \mathrm{r}$. Mlarucchi pisał na ten sam temat: "Scena ta przedstawia raczej zmarłego, umieszczonego na tronio chwały, przez Chrystusa, albo przez męczennika będącego obrończ zmarłego"12. W $1916 \mathrm{r}$. Marucchl jeszcze raz zabrał głos na teilat onawianego obrazu: "Scena tu przedstawiona nie jest aktem przymusu - gwałtu, ale jest spokojnym epizoden, który nie moze sia odnosić do tego okrutnego wydarzenia"13. W 1950 r. pisano o tym obrazie: "iidzimy scenz̨ konsekracjl biskupa w akcie włożenıa rąk"14. Wreszcie w r. 1950 Balboni plsaz "Odniestenie dwóch osób - oznacza leczenie oka"15.

Nie wydaje si\& jednak, by tylko trudność odczytania była powodem trudności $w$ komentowaniu treści sceny malarskiej.żyjz̨cy w XVII w。 oratorianin Pawel Aringhi w swym dziele "flyym podzlemny" tłumaczy prawle wszystrie scony malarskie/także wzięte z zycia codziennego/

9 J.Wilpert, Ein unbekanntes Gemalde aus der h. Domitilla RQ 1/1887/26 i 30; Tenze, Le pitture, 490.

10 D. Balboni, Di una singolare scena grafeita nella eatacomba di Domitilla, R1vaC 32/1955/253-259.

11 Typowiedź Maruccinlego opublikorana "Bullettino di Archeologia Cristiana" $5 / 1880 / 88$ cytuje za Balbonim, art.cyt., 253.

12 Równiez ta wypowiedź opublikowana w "Nuovo Bullettino di Archeologia Cristiana" $21 / 1915 / 136$ cytowana jest za BaIbonim, art. cyt., 254 .

13 Por. Una singolare scona di Simbolismo dommatico sopra un marmo nel ciluitero di Domitilla, "Nuovo Bullettino di Archeologia Cristiana" 22/1916/255.

14 H.Leclerque, Sacramentaires, DACL XV/1, 256.

15 D.Balbont, art.cyt., 259. 
Jako sceny z życia religijnego ${ }^{16}$. Choć przedstawione przez niego narzędzia: piła, oskard 1 młotek mogły siz̨ odnosić do narzędzi pracy zawodowej, to jednak bez zadnych zastrzeżeń kwalifikował je Jako narzędzia męczenistiva ${ }^{17}$. Oratorianie mieli w tym wzglı̨dzie pewną tradycje zakonną, iprowadzonaz przez jednego z największych popularyzatorów katakumb jako skarbca relikwil męczennikóv, św.Filipa Nereusza /1515-1584/.

Nie inną postavę zajmował równiez Maltańczyk Antonto Bosio /1575-1629/18, któremu kopie malowideł sporzędzał malarz Angelo Santint znany pod nazwiskiem Toccafondo. Bosto uważar inalowidła fossorów przy pracy za obrazy nęczeństwa ${ }^{19}$. Należy jednak pamiętać, ze pośmiertnyin wydawcą słynnego dzleła Antoniego Bosio pt. "Rzym podzieriny" - był - jak zaznacza Antoni Ferrua - oratorianin Jan Severano /1562-1640/. Dzleło opublikowano dzięk1 trosce 1 poparciu kardynala Franciszka Barberiniego /1597-1679/. Nie musiały to być jednak względy decydujące, gلyz korzystajįcy z kopii malowideł 1 rysunków tego dziela Flamandezyk Filip Winghe /1560-1592/ nazwar Antoniogo Bosio "kopista najwierniejszym"20. Wiadono rótrniez, ze Severano przed publikacjz wspomnianego dzieła dokonał wim pewnych zinian w swoim duchu. Z innych przeicazów wiadomo, ze Bosio nie zawsze podlegał powszechnie przyjętyin tendencjom. Tak np. Watakumbie św. Cyriaka jest napis na grobie Zuzanny zmarłej w 408 r. w wieku 25 lat, obok lstórego znajduje się znak piły. Według nielstórych współczesnych mu autorór miał to być symbol męczeristwa. Bosio jednak powołujzc się na "Martyrologium Romanum" kardynała Cezarego Baroniusza /1538-1607/ zaznaczył: "Ta piła oznacza raczej narządzie $n$ zawodzie piłowania. kamienia" 21 .

Również Marek Antont Marcantonio/ Boldetti kanonik w bazylico

16 P.Aringhi, Roma subterranea novissima, Roma 1651, 679-712.

17 Tamże 684.

18 A.Ferrua, Bosio Antonio, ECat II 1943-1944.

19 Antonio Bosio, noma sotterranea, Rona 1634, $227,305$.

20 A.Ferrua, Bosio Antonio, 1944.

21 Bosio, dz.cyt., 433. 
Najśr. Maril Panny na Zatybrzu,pełniący przez póz wiecu runkeje papieskiego "Strażnika relikwil 1 cmentarzy", napisal swo dzieło "0 cmen tarzach męczenników 1 starożytnych chrześcijan wzymie", " nastawieniu apologetycznyı. Jak jednak stwierdza Ferrua "zbyt pośpiesznie widział wszędzie męczenników"22. 0 scenach 1konograficznych pisał:

"chodz1 o malowidła w kajlicach 1 na grobach cmentarzy, przedstawiaJące śwį̨tych maczonników tau pogrzebanych, względnie o Inne tajemn1ce czy symbole religil chrześcijaískiej"23. Choć "v trzech rozdziałach swego dzieła pisał o rozwoju malarstwa, o jego typach, o motywach konfesyjnych poyaúskich 1 chrześc1jańskich, to jednak pominął zupełnie tematykę życia świeckiego ${ }^{24}$. T.Roller skrytykował powyższą metodę, wedługr której wszędzie upatrywano symboli męczeństiva. Pisał, ze Już przeciez 1 poganie przedstawiall w swej lkonografil cmentarnej większiz częsé narzędzi bez odnoszenia lch do męczeństwa; starożytnośs pogańska nio wynalazła jakichś nowych narzęuzi do torturowania chrześcijan. Autor przy tym nie ustrzegł sie od rozdziału pt. "Instrunenty męczenistwa"25, wśród których znalazła się 1 piła ${ }^{26}$.

0 Wilpercie wspominaliśmy już na poczłtku. Zlarał on sobie sprawe, ze wiolu autorów korzystało z kopil zabytków nie zawsze autentycznych. San stosowaz metode porórnawcza, w kytyce zaś zabytku, o ile to było możliwe, uwzględniał tez tésty 1 całe środowisko. W swym magistralnym dzielo o malarstwio kataisumbowym ukazal fossorów, piekarzy, sprzedawcę jęczintenia, sprzedawce warzyw, wioślarzy, bednarzy, uprawiajįcego winnice, cyrkowego woźnicę, zołnierza 27 , zaznacza-

22 A.Ferrua, Boldett1, Sarcantonio, ECat II 1771.

23 M.A.Boldetti, Osservazioni sopra 1 cimiteri dei martiri ed antichi cristiani di liona, Koma 1720 , t. 1,17 .

24 Tauże 17-29.

25 T.Roller, Les catacombes de llome. Illotorie de l'art et des croyances relísicuses pendant les premiers siècles du christianisme, Paris 1881, t. 1, 21-23.

26 Tanże 21.

27 Filpert, Le pitture: fossorowie 476-479; plekarze 485-437; sprzedawca jęczmienia 487-488; sprzedawca warzyw 489; wioślarze 489-493; beduarze 490; uprawiajzcy winnice 490-493. 
Jąc, te na pomnikach grobowych chrześcijan spotyka sie "sceny wzlęte z zycia zienskiego zmarłych ... 1 sceny o zawodachn" ${ }^{28}$. W praktyce kontynuował metodą swych poprzedników, chociaz był moźe jedynym, który z racjl sivej wiedzy mógłby owe sceny tłumaczyć w szerszym kontekście. Twierdzit, ze chrześcijanie nie dbali o sceny z zycla świecislego, a bardziej Interesujacymi lch tematami były takie zagadnienia jak: zbawienia duszy, miłosierdzie Boga, postać Chrystusa ja ko Boga ${ }^{29}$. Ale równiez 1 Wilpert po stwierdzeniu autentyczności sceny, szukał za wszelkz cenz sensu symbolicznego. Uwidacznia sie to wyraźnte w komentarzu do Possorów w Katakumbie św.Kaliksta ${ }^{30}$, gdzie plekarze nie są przedsta:ient jako pracujacy, ale ukazani tylko dla poukreślenia godności lch zawodu. Obecnośd kosza z chlebami jest tłunaczona: "piekarze chciel1 przypomnieć widzow1, ze onl dostarczy11 chleba dla oflary ołtarza" ${ }^{31}$. Podobnie znak beczki mlaz byé tylko aluzjz dla wykonywanta zawodu 32 .

Innym wreszcie sposobem symbolicznego tłumaczenta narzędz 1 zawodorych było zastosowanie tzw. "malowidez mówlacych". Przedstawicielem tego kierunku był jezuita Rafael Garrucci/1812-1885/, Który w swym trzytomowym monumentalnym dziele "Ilistoria sztuk1 chrzesc1jańskiej w plerwszych ośmiu wiekach Koścloła" zebrał całe patrymonium artystyczne chrześcjjaístwa. Utrzymywal, ze narzęzia pracy zawodowej przedstaniaja narzędzia męlk ${ }^{33}$. Az 23 rozdziały pierwszego towu pośvigcił symbolizmowi ${ }^{34}$. Rozdzlal natomiast 16 omaw 1 a tematyke "syıbol1 mówiących"35. Garruoo1 tak spreoyzowal to zagadnienie: "Nazywamy narzędziani zabijania tj. symbolami mówlacymi te przedmioty, które przedstawiaja postaciowo to, co oznacza nazwa; przedmio ty, których użcie było znane chrześcijanom 1 znalazło wyraz w $1 \mathrm{ch}$

28 J. Wilpert, I sarcofagi cristian1 ant1ch1, lioma 1932, 338-339;

Balboni, art.cyt., 257 .

29 Wilpert, Le pitture 492.

30 P.Stopniak, Starochrześcijańskie kolegla fossorów, STV 17/1979/ 207-223, szczególinie 217 .

31 Wilpert, Le pitture 486.

32 Tamze 490.

33 R.Garrucc1, Storia dell'arte cristiana nel primi otto secoli della Ch1esa, Prato 1872-1876, t.1, 222-232.

34 Taraze 151-210.

35 Tamże 219-221. 
pomnikacil. Koza /capra/ jest na powno syribolem mówiącym kobiety imieniem Capreola". Podavat ponadto szereg podobnych przykładów ${ }^{36}$. P1sząc zaś o zyciu zawodowym zaznaczył: "Chrześcijanie umieszczali nie jednokrotnio w napisach lub obok nich symboliczne znaki zawodowe, względnie symbole wyznania" ${ }^{37}$.

3. E w o l u c ja p o g 1 a d ó w. Nieco inną była genoza rozwoju badań w zakresie życia zawodowego, która jednak nie łączy się wprost z dorobkien wymlentonych autorów. Głównym bodźcem do $1 \mathrm{ch}$ rozpocz ̨̧cia stały siq wydawnictwa starożytnych inskrypoji pogańskich 1 clurześcijańskich. Dwanaście 1 ch kolekcj1 takich wydawców jak: Jan Gruyter /+1627/, Tomasz Reines1o /+1667/, Jan Baptysta Doni /+ 1647/ Franciszek Gori / $1757 /$, Markwardt Gudius $/+1689 /$, Rafael Fabrett1 í 1700/, Franciszek Scip1o Laffei /1675-1755/, Gaspar Ludwik Oderyk /+ 1803/zawierało juz w $1835 \mathrm{r}$. ponad 60 tysiegey Inskrypcji ${ }^{38}$. Utworzenie w $1829 \mathrm{r}$. Instytutu Archeologicznego w Rymie, a w nim praca takich uczonych, jak inicjator wydania "Corpus Inscriptionum Latinarum" Teodor Monmsen oraz Y1lhelm Henzen $i$ J.B. Rossi doprowadziło liczbę wydanych inskrypeji w konicu XIX w. do liczby blisko 150 tysięcy, tak poganiskich, Jak 1 chrzesicijaliskich. Jednyin z pierwszych rezultatów z uzyskanego zbioru inskrypej1 by ło uśriadomiente 1stnienia w starozytnosici rolektywnej struktury zawodorej. Pojawiła sie mnogość prac badawczyci na ounawany temat, rozkwit tego piśmiennictwa przypala na 2. poł. XIX w. lizglidnz cezurg chronologicznz stanow tu rok 1870. Rok przedtem uczeni francuscy opuśctli Instytut Archeologiczny w Rymie 1 zalozyll we Francji szkole archeologicznohistoryczna, w której od połowy XIX w. publikowano sporadycznie prace o życiu zawodorym ${ }^{39}$. Od roku 1870 głównym tomatem 1 ch badál staky

36 Tante 219.

37 Tanze.

38 M.René de la Blanchere, Histolre de l'épigraphie latine depuis des or 1 gines jusqu'à la publication du Corpus, Paris 1887, 21.

39 Siz to prace takich liczonych jak: J.Rabanis /1841/: J.Belin Siz to prace takich uczonych jak: J.Rabanis $/ 1841 /$; $/$ Belin $/ 1878 /$; N.Botton /1882/; J.Drious /1884/; M.Duse1gneur /1886/; 0.Steinier /1887/; D.Calinesco/1890/; P.Tronette/1892/; P.Lablat $/ 189 /$ L.Joly $/ 1893 /$. 
sie kolegia zawodowe w starozytności, a w tym prace nad poszczególnymi zarodani zrzeszonymi'w kolegiach. Synteze tych prac podał J.Waltzing w 4 tomowym dzlele wydanym w Lowanium ${ }^{40}$. Obolk tego główny wysiłek uczonych niemieckich zwracal się do rozwiazania problemu technik1 pracy zawodowej, owocem czego było znów 4 tomowe, zbiorowe dzieło o technologii 1 terminologii 41 , wględnie zawierajaca wiele materiału pomocniczego 4 tomora praca F.Friedilundera o zyciu obyczajowym w Rzymie ${ }^{42}$. Choć wielu autorów powyzszych syntez nie zajmowazo się bezpośrednio tematyka chrześcijaíska, to jednak byl1 oni zmuszeni do wykorzystania takze dokumentacji chrześcijańskiej.

Rossi jako jeden z wyżej wspomnianych organizatorów nauki, stał sie załozycielem tzw. szkoły rzymskiej. Był tez plerwszym naukowym badaczem w dziedzinie archeologil chrześcijańskiej, dzięki swej metodzie, polegajacej na wszechstronnoj analizio badanych zabytkóm. Odnośnie do nalowidez, w przecivieństwie do Boldettiego, opiniowat: "W 1stocie, znaki same nie moga byé uważane za vyraźne dowody męczenístra"43. Kiedy np. Boldetti identyfikował jaliźs scenę z meczeństien przez "obcegl oz ozsteczka oderianego ciała", Ross 1 odczytywał ten sam zabytek jalso "szçypce z wyrwanym zqber, znak1em zmarzego chirurga" ${ }^{44}$. Rezultaty badań Rossiego nad fossorami, mimo upływu ponad 90 lat od wydania 3 tomu jego "Roma sotterranea", zachowały nadal swe znaczenie. Od jego czasów znaki wyryte na płytach grobowych zaczęto uwaźá za atrybuty wykonyranego zawodu.

40 J.P.Waltzing, Etude historique sur les corporations professionelles chez les Romains dopuis les origines jusqua la chute de 1 Empire d Occident, Bruxelles/1895-1900/.

41 Technologie der Gewerbe und Kunste be1 Griechen und nomern, Leipzig 1874-1887. Można tu przy okazji wskazać na analogiczno współczesne przyczynki polskie, opublikowane w "Acta conventus XI "EIrene" z kongresu studiów klasycznych PAN /21-25 X 1968/, gdzie w opublikowanyci w $1971 \mathrm{r}$. materiatach jest kilka sprawozdań badaczy polskich o pracy zawodowej niektórych speojalności z okresu cesarstwa.

42 F. Friedlunder, Darstellungen aus der Sittengeschichte lloms in der. Zeit von August bis zum Ausgang der Antonine, Leipzig 1919$1920^{9}$.

43 G.B. De Rossi, Scoperte nella basilica di S.Lorenzo nell' agro Verano, "Bullettino d1 Archeologia Crist1ana" $2 / 1864 / 37$.

44 Tamżo. 
Interesujący jest komentarz T.Rollera o grupie ponników pochodzenia civentarnego umieszczonych przez Rossiego w Muzeum Lateraneńskim. Tryerdził on za nim, ze każemu narzędziu zaznaczonemu na tablicy, odpowiada stosowny zawód ${ }^{45}$, za czym wypowiedzieli sie prawie wszyscy jego uczntowic. On tes pierwszy zaczuł publikować krytycznie opracowane 1nskrypcje. Poza 6 tomani, które włączył do wspomnianego "Corpusu", wylał 2 tomy inskrypejt chrześcijańskich spoza Rzymu; jego prace w tym zakresie nadal sa kontynuowane. I pierwszym tomie inskrypcjl E.Diehla matny juź część napisów zestawionych według określeń tekstowych napisu 1 znaków - symbol1 zawodu ${ }^{46}$. Do tak1 ch uzupeznień należiz także prace Ferruy 1 innycin ${ }^{47}$.

Stan badaí nad postawionyin zagadnteniem nie jest jeszcze zakończony, choć lch owoce referowane w postaci krótkich komunikatów, np. A. Ferruy przynoszy wprost rewelacyjne wynik1. Jak trudne sa te badanıa wskazujiz choćby prace nad znakiea "ascia" - narzędzia zblizonego zastosowanien do slekiery wzlgdnse kilofa. Ponad 400 prao naukowych $z$ ostatnich trzech wieków poswieconych ustaleniu znaczenta tego narzędzıa na pomnikach kultu zmarłych w zasadzie nie dało pełnego rozwiazania 48 , owszem raczej zantejsza sle szansa rozilizania togo konkretnego zagadnienia.

Podobno badania poza względem czysto naukowym, moga mié wkład także do rozłoju doktryny chrzościjańskioj. Jals dotąd za mało wiemy o strukturze plerwotnej giulny chrześcijańskiej. Byé możo dokładne studium wczesnych kodelsów prawnych 1 literatury patrystycznoj pozwo11 na poszerzenie bazy źródłowej. Same inskrypcjo sa zbyt późne chronologicznie, by wogly wypolnid luke w tej dziedzinte wiedzy.

W powyższym artykule starano sie jedynie zwróclé uwage na ewolucje kowentarza naukorego dotyczącego tłumaczenia znaków zawodu. Od

45 T.Moller, dz.cyt., t. 2, 33-38.

46 E.Diehl, Inscriptiones Latinae christianae veteres, Berlin 1961, nr $393-749$.

47 A.Ferrua, Liber l'auriga del circo, "La Civiltà Cattolica" 98 /1947/t.2, 438-447.

48. F.Stopniak, Starochrzé́cijańskie kolegia fossorów, art. cyt., 218222 . 
powszechnego tłumaczenia tych znaków w sposób teologiczny, przypisuJący im symbolikę męczeństwa, od końca XIX $w$. zacz ż przeważać komentarz historyczny, polegajacy na uznawantu malowanych lub rytych obra.. zóm narzędzi za znaki tozsamości zmarłych, grzebanych pod odporyiedn1a tablica grobowa.

$$
\text { Ks. Franciszek Stopniak - Warszawa }
$$

\section{INSTRUAENTE DER BERUFGARBEIT IN DER MÄRTYRERSYMBOLIK /Zus ammenfassung/}

Nach elner einfahrenden Erklarung der Begriffe 1st der Autor in seinem Artikel darum bemtht, auf die Evolution des wissenschaftlichen Kommentars betreffs der Erlduterung der Leidonsinstrutnente und Berufszeichen in der Katakombenmalerei und auf den Grabtafeln aufmerksam zu machon. Diese Zeichen wurden zuntchst allgenein erk1 lut; auf theologische lielse schrieb man ihnen eine MArtyrersymbolik zu. Se1t Ende des 19. Jahrhunderts begann der historische Konnentar vorzuherrschen; er beruht auf der Anerkennung der geinalten und gravierten Instrumentenbilder als Identitutszelchen der unter der entsprechenden Grabtafel begrabenen Toten. 